Article

\title{
Psychometric Properties and a Multiple Indicators Multiple Cause Model of the Career Aspiration Scale with College Students of Rural Thailand
}

\author{
Jetnipit Kunchai $^{1}$, Dissakoon Chonsalasin ${ }^{2} \mathbb{D}$ and Buratin Khampirat ${ }^{1, *(\mathbb{D})}$ \\ 1 Institute of Social Technology, Suranaree University of Technology, Nakhon Ratchasima 30000, Thailand; \\ d6020187@g.sut.ac.th \\ 2 School of Transportation Engineering, Institute of Engineering, Suranaree University of Technology, \\ Nakhon Ratchasima 30000, Thailand; dissakoon@sut.ac.th \\ * $\quad$ Correspondence: buratink@sut.ac.th; Tel.: +66-8173-5219-7
}

Citation: Kunchai, J.; Chonsalasin, D.; Khampirat, B. Psychometric Properties and a Multiple Indicators Multiple Cause Model of the Career Aspiration Scale with College Students of Rural Thailand. Sustainability 2021, 13, 10377. https:/ / doi.org/10.3390/su131810377

Academic Editor: Jérôme Rossier

Received: 31 July 2021

Accepted: 13 September 2021

Published: 17 September 2021

Publisher's Note: MDPI stays neutral with regard to jurisdictional claims in published maps and institutional affiliations.

Copyright: (c) 2021 by the authors. Licensee MDPI, Basel, Switzerland. This article is an open access article distributed under the terms and conditions of the Creative Commons Attribution (CC BY) license (https:// creativecommons.org/licenses/by/ $4.0 /)$.

\begin{abstract}
To help address educational inequalities in student backgrounds and career plans, the measurement of career aspirations can provide crucial information about inequality related to career opportunities. Therefore, this study analyzed the factor structure and psychometric properties of the Career Aspiration Scale-Revised (CAS-R) and the effects of sociodemographic variables on the CAS-R. The study participants were 590 undergraduates at three community colleges in rural Thailand. Confirmatory factor analysis (CFA) was conducted to investigate the validity of the CAS-R three-factor model. The Multiple Indicators Multiple Causes (MIMIC) model with and without differential item functioning (DIF) were applied to investigate the effects of sociodemographic factors as covariates on the CAS-R and specific item response. The CFA results supported the 18-item CAS-R's three-factor structure because the items well represented latent factors and because the subscales met research standards for reliability and validity. The MIMIC model showed that only the year of study (first-year students) had a positive direct effect on leadership, achievement, and educational aspirations. The MIMIC model with DIF indicated that gender, year of study, major, and paternal education caused inequality in 10 items. Overall, the results show that the 18 -item CAS-R has strong psychometric properties and can accurately assess the career aspirations of Thai students. The MIMIC model's application allowed researchers to show that sociodemographic background affected the leadership, achievement, and education subscales. Obtaining information on the CAS-R scale's measurements would be useful for researchers, practitioners, and career counselors interested in helping students develop career aspirations and choices.
\end{abstract}

Keywords: confirmatory factor analysis; differential item functioning (DIF); Multiple Indicators Multiple Causes (MIMIC); educational aspiration; achievement aspiration; leadership aspiration

\section{Introduction}

Recognized as critical in student career development theory [1], career aspirations are linked to an individual's self-concept, career goals, academic achievement, and work performance [2,3]. According to Sewell et al. [4], career aspirations are a driving force associated with action behaviors that motivate individuals to achieve goals. According to Gottfredson's theory [5], career aspirations are a process of socialization that develop from early childhood to adolescence, and social cognitive career theory (SCCT) [6] recognizes to the importance of career aspirations in the career decision-making process and in career planning. Indeed, career aspiration is a complicated structure that requires different levels and areas of development-family, educational institution, and social level, that impacts lifestyle and career goals [1,7]. Encouraging and motivating students to further their career aspirations [2] can help them develop professional skills, expand sustainable career choices, and increase competitiveness in the labor market [7]. In addition, the COVID-19 
pandemic may currently affect student career aspirations, influencing their career choice opportunities, career behaviors, and mental health [8]. Maintaining high career aspirations may also support how students focus on improving themselves, possibly leading to better career opportunities [9]. Contextual factors and cognitive personal include traits such as gender, cultural variables, socioeconomic status, expectancies, self-efficacy, and learning environments [10-12].

Career aspirations have been widely recognized in career psychology studies in many countries. In Thailand, Khampirat [7] showed that university students whose fathers had lower educational levels had lower career aspirations than those whose fathers had higher levels of education. Khampirat [13] also compared career aspiration means between first- and fourth-year students and found that the scores of fourth-year students were higher than those of first-year students in all aspects. Weeranakint and Sungsanit [14] reported how the career aspirations of Thai female managers were associated with selfefficacy and organizational types. The study of Ulrich et al. [15] showed a correlation between social environment (i.e., parents, teachers, friends) and career aspirations in Thai adolescents. Powell et al. [16] reported that Thai educational institutions did not emphasize the importance of student career aspirations because Thai culture emphasizes humility, politeness, and peace.

Reyes et al. [17] investigated the career aspirations of Mexican-American teenagers from low-income backgrounds, finding that females had higher aspirations than males. Fouad and Byars-Winston's meta-analysis [18] concluded that race and/or ethnicity differences did not affect career aspirations, but minorities perceived fewer career opportunities and more occupational barriers than non-minorities. In Ghana, Owusu et al.'s [19] research found that parents had a major influence on student career aspirations. In India, Sapra et al. [20] indicated that university students in management programs had high career aspirations but that they were not of a reasonable level, and these goals had a low relationship with academic performance. In Uganda, a qualitative survey by Ampaire et al. [21] revealed that student career choices were based on career aspirations and student interests. In the United Arab Emirates, Cairns and Dickson [22] suggested that the STEM career aspirations of 15-year-old students had a positive relationship with science achievement. In the USA, Gregor et al. [23] indicated that college student career aspirations were influenced by career-decision self-efficacy, compromising their career for a partner, perceptions of barriers, and coping efficacy in overcoming barriers.

Hence, to help address educational inequalities related to background factors and career aspirations, the measurement of college student career aspirations achieves accurate pictures of inequality related to career opportunities and career decision self-efficacy [24-26], especially because based on diverse measurements and criteria, levels of career aspiration vary across areas and contexts. Improved measurement instruments are therefore essential for comparing research findings.

To assess the career aspirations of women in the United States, O'Brien [27] developed the Career Aspiration Scale (CAS), which has been revised as the CAS-R to provide better psychometric properties and to assess leadership, achievement, and educational aspirations [28]. CAS and CAS-R have been implemented in varied studies, for example: in Chinese schools [29], with Korean students [30,31], in Indonesian high schools [32,33], in US colleges [23,34,35], Pakistani colleges [36], with Indian adolescents [37], with collegeeducated Indian women [38], in a Thai university [7,13], in Thai secondary schools [39], Omani schools [2], and Chinese colleges [40]. Although the CAS-R has demonstrated adequate reliability and validity and has also been proven valid in various contexts, factor structure and psychometric properties have not been consistent across studies. One- to three-factor models have been identified for the CAS-R, but no studies have investigated the Multiple Indicators Multiple Causes (MIMIC) model or have considered such measurement bias as a differential item functioning (DIF), that is, a MIMIC model affected by age, gender, and level of education, in which DIF can examine the scale at the item level to check for biased between-group comparisons because response patterns might reflect 
sociodemographic factors [41].Therefore, to fill in gaps left by previous studies, the present study aimed to:

(1) Analyze the CAS-R's factor structure and psychometric properties among college students in rural Thailand;

(2) Once the CAS-R's most suitable measurement model has been determined, identify important sociodemographic background factors by applying the MIMIC model with and without DIF.

\section{Materials and Methods}

\subsection{Participants}

The study participants were 590 ( $55.08 \%$ female; $44.92 \%$ male) undergraduates at three community colleges in central Thailand, most of them from rural areas (Figure 1): 17.29\% first-year, $12.88 \%$ second-year, $28.98 \%$ third-year, and $40.85 \%$ fourth-year students. Majors of study varied, with approximately half of the students studying in an engineering and technology program $(57.29 \%), 31.53 \%$ studying in a social science program, and $11.19 \%$ studying in a science program. The majority of the participants' parents had educational levels lower than a bachelor's degree (Table 1).

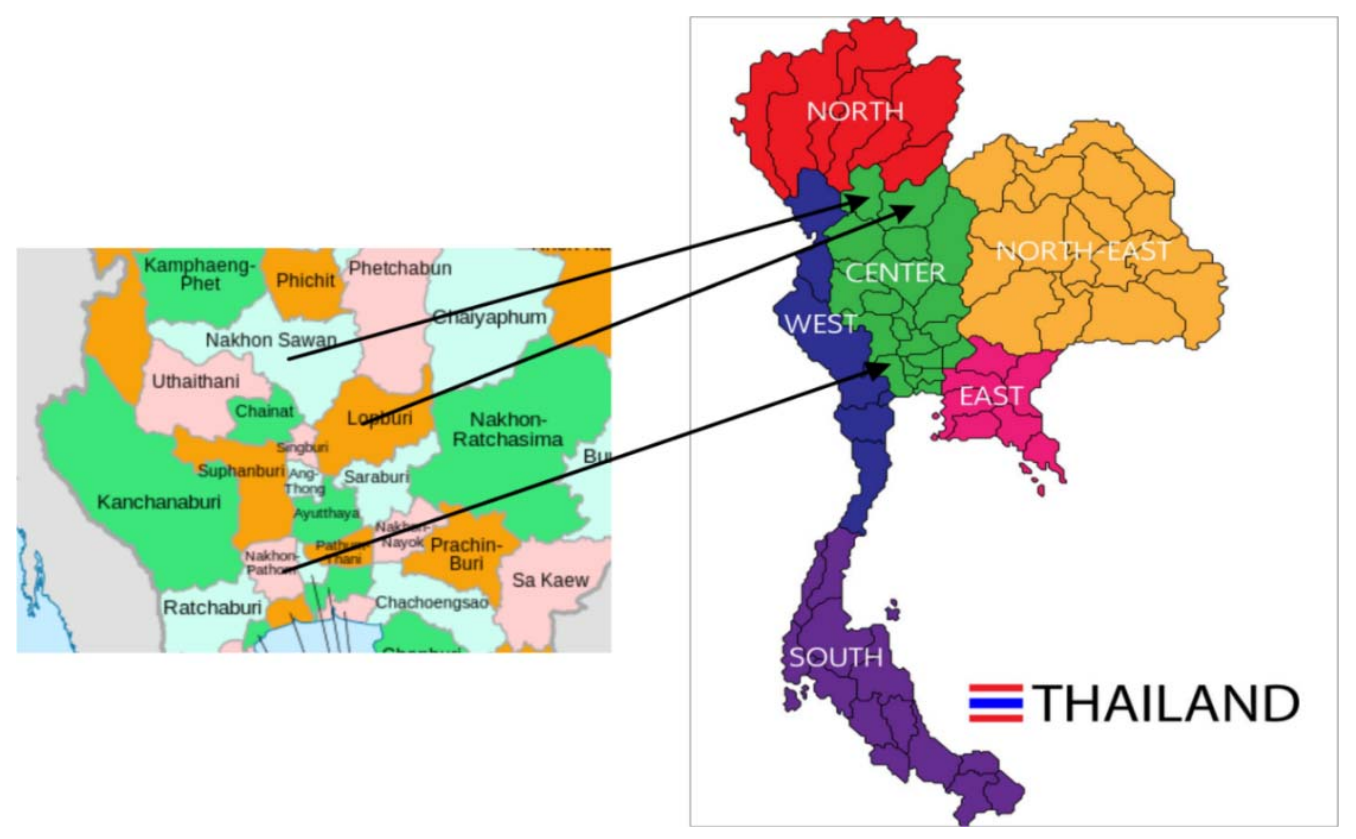

Figure 1. Map of Thailand and the survey area. 
Table 1. Participants' sociodemographic statistics $(N=590)$.

\begin{tabular}{|c|c|c|c|c|}
\hline Variable & Code Description & Category & $N$ & $\%$ \\
\hline \multirow[t]{2}{*}{ Gender } & 1 if female (reference group); & Female & 325 & 55.08 \\
\hline & $0=$ otherwise & Male & 265 & 44.92 \\
\hline \multirow[t]{4}{*}{ Year of study } & & 1st-year & 102 & 17.29 \\
\hline & 1 if first-year student (reference group); & 2nd-year & 76 & 12.88 \\
\hline & $0=$ otherwise & 3rd-year & 171 & 28.98 \\
\hline & & 4th-year & 241 & 40.85 \\
\hline \multirow[t]{3}{*}{ Major } & \multirow{3}{*}{$\begin{array}{l}1 \text { if major in social science (reference group); } \\
\qquad 0=\text { otherwise }\end{array}$} & Engineering and Technology & 338 & 57.29 \\
\hline & & Science & 66 & 11.19 \\
\hline & & Social Science & 186 & 31.53 \\
\hline \multirow{2}{*}{$\begin{array}{l}\text { Type of high school } \\
\text { students graduated }\end{array}$} & \multirow{2}{*}{$\begin{array}{l}1 \text { if private high school (reference group); } \\
\qquad 0=\text { otherwise }\end{array}$} & Public high school & 502 & 85.08 \\
\hline & & Private high school & 88 & 14.92 \\
\hline \multirow{4}{*}{$\begin{array}{l}\text { Area of high school } \\
\text { where students } \\
\text { graduated }\end{array}$} & & Sub-district & 27 & 4.58 \\
\hline & & District & 251 & 42.54 \\
\hline & & Province & 237 & 40.17 \\
\hline & & Capital City & 75 & 12.71 \\
\hline \multirow[t]{9}{*}{ Paternal education } & 1 if bachelor's degree and higher (reference & Kindergarten & 4 & 0.68 \\
\hline & group); & Elementary school & 222 & 37.63 \\
\hline & $0=$ otherwise & Lower-secondary & 100 & 16.95 \\
\hline & & Upper-secondary & 131 & 22.20 \\
\hline & & Training for career & 15 & 2.54 \\
\hline & & High vocational diploma & 48 & 8.13 \\
\hline & & Bachelor's degree & 62 & 10.51 \\
\hline & & Master's degree & 6 & 1.02 \\
\hline & & Doctorate degree & 2 & 0.34 \\
\hline \multirow[t]{9}{*}{ Maternal education } & & Kindergarten & 4 & 0.68 \\
\hline & & Elementary school & 242 & 41.02 \\
\hline & & Lower-secondary & 95 & 16.10 \\
\hline & & Upper-secondary & 125 & 21.19 \\
\hline & & Training for career & 12 & 2.03 \\
\hline & & High vocational diploma & 42 & 7.12 \\
\hline & & Bachelor's degree & 60 & 10.17 \\
\hline & & Master's degree & 9 & 1.52 \\
\hline & & Doctorate degree & 1 & 0.17 \\
\hline
\end{tabular}

\subsection{Measures and Instrument}

Sociodemographic data: The survey requested information from five areas: (1) gender, (2) year of study, (3) major, (4) type of high school, (5) area of high school, and (5) father and mother's highest educational level as a proxy for socioeconomic status.

Career Aspiration Scale-Revised (CAS-R): The CAS-R [28] is a revised version of O'Brien's original [27] self-reported questionnaire of 24 items measuring three subscales of career aspirations including leadership (8 items), achievement (8 items), and education (8 items). Items are rated on a 5-point Likert-type scale ranging from 1 (not at all true of me) to 5 (very true of me). Included were five negative items about achievement (ACH6 and ACH8) and leadership aspirations (LEA2, LEA3, and LEA6). For all negative items, reverse scoring was determined before analysis. For this study, each factor's mean scores were utilized; means were obtained by combining all items for a total score and were then dividing by the number of items. Higher scores on the CAS-R reflect a greater degree of career aspirations, and lower scores indicate a lack of perceived self-career aspirations. For responses rated from 1 to 5 and the scale's range of $4(5-1=4)$, when the range was divided by the maximum scale value $(4 \div 5=0.80)$, the following criteria were used to interpret the weighted mean: 1 to $1.80=$ strongly disagree, $1.81-2.60=$ disagree, $2.61-3.40=$ neutral, 3:41-4:20 = agree, and 4:21-5:00 = strongly agree [7,42]. The Cronbach's alpha coefficients 
for the three subscales showed an acceptable level of reliability, ranging between 0.761 and 0.916 (see Table 2). For the construct validity, the CAS-R fitted the data fairly well, $\chi^{2}=619.215, d f=226, p=0.000, \chi^{2} / d f=2.740, \mathrm{CFI}=0.954, \mathrm{TLI}=0.943, \mathrm{RMSEA}=0.054$ (95\% CI: $0.049-0.059$ ).

Table 2. Mean, standard deviation, and correlation matrix of constructs and variables in the model.

\begin{tabular}{|c|c|c|c|c|c|c|c|c|}
\hline \multirow{2}{*}{ Variables } & \multicolumn{8}{|c|}{ Correlation Coefficient between Variables in MIMIC Model } \\
\hline & 1 & 2 & 3 & 4 & 5 & 6 & 7 & 8 \\
\hline 1. Leadership aspirations & 1.00 & & & & & & & \\
\hline 2. Achievement aspirations & $0.82 * *$ & 1.00 & & & & & & \\
\hline 3. Education aspirations & $0.69 * *$ & $0.79 * *$ & 1.00 & & & & & \\
\hline 4. Female & $-0.11^{* *}$ & -0.08 * & $0.09 *$ & 1.00 & & & & \\
\hline 5. First-year student & $0.13^{* *}$ & $0.12 * *$ & $0.19^{* *}$ & -0.06 & 1.00 & & & \\
\hline 6. Private high school & 0.07 & 0.04 & 0.02 & -0.04 & -0.07 & 1.00 & & \\
\hline 7. Major in social science & -0.07 & -0.02 & $0.11 *$ & $0.28 * *$ & 0.07 & $-0.12^{* *}$ & 1.00 & \\
\hline 8. Paternal education & 0.06 & $0.08^{*}$ & 0.06 & 0.02 & 0.00 & -0.05 & $0.15^{* *}$ & 1.00 \\
\hline$M$ & 3.14 & 3.25 & 3.48 & 0.55 & 0.17 & 0.15 & 0.32 & 0.12 \\
\hline$S D$ & 0.63 & 0.66 & 0.78 & 0.5 & 0.38 & 0.36 & 0.47 & 0.32 \\
\hline$\alpha$ & 0.761 & 0.781 & 0.916 & & & & & \\
\hline
\end{tabular}

Note: ${ }^{*}=p<0.05 ; * *=p<0.01$.

\subsection{Data Analysis}

Statistical procedures were performed using SPSS for Windows version 18.0 and Mplus 8.3. First, descriptive statistics were calculated to describe the participants' basic sociodemographic characteristics and the measures. Pearson's correlation $(r)$ matrix was constructed to examine relationships between the model's variables [43]. Second, to investigate the CAS-R's factor structure and psychometric properties, confirmatory factor analysis (CFA) was conducted to verify the structure or relations between the measured variables and factors (latent constructs) and to investigate construct validity. In this analysis, a three-factor model was specified and tested (Figure 2). Finally, a MIMIC model was applied [44,45], or CFA with covariates was performed to explore construct validity by simultaneously estimating the influence of five possible covariates on the three CAS-R subscales and the DIF effect [46,47]. The three-factor MIMIC without the DIF model was tested first, and then DIF detection was employed to examine the direct path of the covariates on specific item responses (indicators). The five sociodemographic variables were used as covariates in the MIMIC model: gender (male as the reference group), year of study (first-year students as the reference group), type of high school (private high school as the reference group), major (social science as the reference group), and paternal education (bachelor's degree and higher as the reference group).

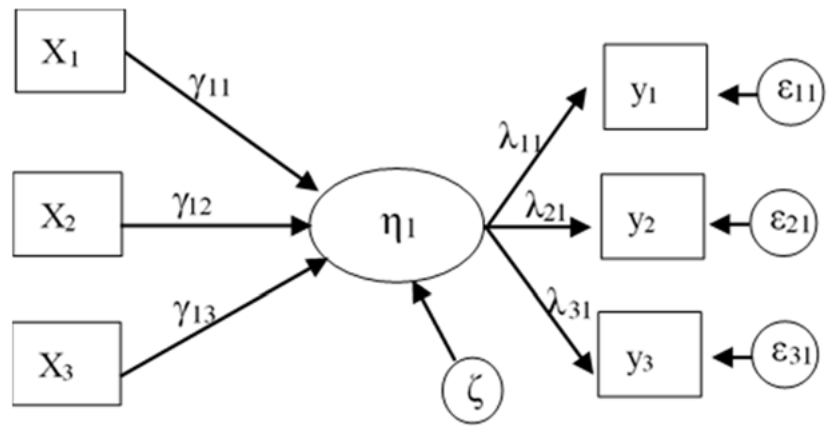

(a)

Figure 2. Cont. 


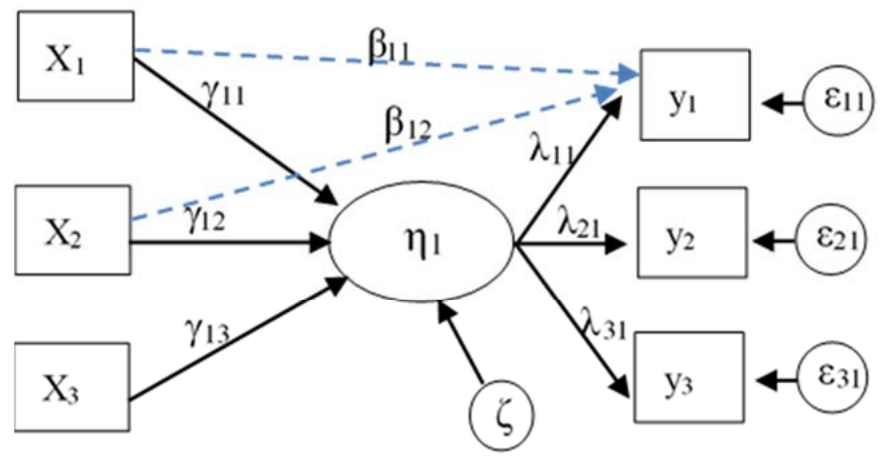

(b)

Figure 2. (a) MIMIC model and (b) MIMIC model with DIF.

\subsection{MIMIC Model's Specification}

The MIMIC approach is a type of structural equation modeling that describes the effects of covariates on latent variables as well as their interrelationships, providing more insight than typical correlational analysis. The proposed MIMIC model was described by the reflective and formative measurement equations are Equations (1) and (2), respectively:

Reflective measurement model equation:

$$
Y_{i j}=\lambda_{i j} \eta_{j}+\epsilon_{i j}
$$

Formative measurement model equation:

$$
\eta_{j}=\gamma_{k} X_{i k}+\delta_{i}
$$

where $Y_{i j}$ is the reflective item $i$ of the latent factor, $\left(\eta_{j}\right) ; \lambda_{i j}$ is a factor loading of item $i ; \eta_{j}$ is a latent factor $j$; $\varepsilon_{i j}$ is the random error term of indicator. In the formative measurement model equation, $\gamma_{k}$ is an estimated coefficient of covariate $k ; X_{i k}$ is a formative or causative indicator that affects the random error $\left(\eta_{j}\right) ; \delta_{i}$ is the random error term of the construct.

The MIMIC model with DIF can be expressed as the following $[48,49]$ :

$$
Y_{i j}=\lambda_{i j} \eta_{j}+\beta_{i k} X_{k}+\epsilon_{i j}
$$

In this model, $Y_{i j}, \lambda_{i j}, \eta_{j}$, and $\varepsilon_{i j}$ are defined in Equation (1); $X_{k}$ is a covariate $k$ (either continuous or categorical variable); and $\beta_{i k}$ is a regression coefficient relating to covariate $X_{k}$ on item $i$. If $\beta_{i k}=0$, then item $i$ is homogeneous across covariate $X$; that is, there is no item bias or a non-uniform DIF effect. On the other hand, a significant $\beta_{i k}$ indicates a direct effect of $X$ on $Y_{i j}$; thus, a uniform DIF is found in item $i[48,49]$.

To assess construct validity, the measurement's degree of fit and MIMIC models were used to examine how suitable the theoretical model was for empirical data. Various fit indices were employed, e.g., the ratio of chi-square goodness-of-fit per degree of freedom $\left(\chi^{2} / d f \leq 5\right)$, the comparative fit index (CFI $\left.\geq 0.95\right)$, the Tucker-Lewis index $(\geq 0.95)$, the root mean square error of approximation and a 90\% confidence interval (RMSEA < 0.08), and the standardized root mean squared residual (SRMR $\leq 0.10$ ) [50]. A good relationship between items and their factors is indicated by a standardized factor loading greater than 0.5 with a $p$-value of less than 0.05 [51].

\subsection{Procedure}

This cross-sectional study was conducted from April 2018 to August 2019. The research team collected data in several places, for instance, in classrooms, cafeterias during lunch breaks, and meeting rooms. Survey participation was voluntary, and respondents were informed that they could withdraw at any time. Responding to the questionnaire took 
approximately 10-15 $\mathrm{min}$, and the researcher clarified that the questionnaire responses did not contribute to learning or test scores in any way. The ethics statement was approved by the Suranaree University of Technology, Thailand (No. EC-63-0017). The following items were included in the survey questionnaire: statements related to the research process; a description of the research benefits; a consent form; assurance of participant confidentiality and anonymity; and the provisions of the researchers' contact information for additional information and requests for research output.

\section{Results}

\subsection{Descriptive Statistics and Correlation Coefficients}

The means $(M)$, standard deviations $(S D)$, skewness $(S K)$, and kurtosis $(K U)$ of CAS$\mathrm{R}$ and items are presented in Table 3. Students reported the highest levels on items LEA5 $(M=3.603, S D=1.00)$ for leadership aspirations, ACH3 $(M=3.576, S D=0.972)$ for achievement aspirations, and EDU2 $(M=3.595, S D=0.996)$ for educational aspirations, while assessing themselves the lowest in LEA2 $(M=2.715, S D=1.062)$, ACH6 $(M=2.561$, $S D=1.275)$, and EDU5 $(M=3.366, S D=0.951)$ for leadership, achievement, and educational aspirations, respectively.

Table 3. Descriptive statistics.

\begin{tabular}{|c|c|c|c|c|c|c|}
\hline Code & Items & $M$ & $S D$ & $S K$ & $K U$ & CITC \\
\hline & Leadership aspirations & & & & & \\
\hline LEA1 & I hope to become a leader in my career field. & 3.281 & 0.981 & -0.155 & -0.165 & 0.496 \\
\hline LEA2 & $\begin{array}{l}\text { I do not plan to devote energy to getting promoted to a leadership } \\
\text { position in the organization or business in which I am working. }\end{array}$ & 2.715 & 1.062 & 0.067 & -0.562 & 0.365 \\
\hline LEA3 & Becoming a leader in my job is not at all important to me. & 2.798 & 1.091 & -0.010 & -0.595 & 0.419 \\
\hline LEA4 & $\begin{array}{l}\text { When I am established in my career, I would like to manage other } \\
\text { employees. }\end{array}$ & 2.973 & 1.032 & -0.085 & -0.321 & 0.460 \\
\hline LEA5 & $\begin{array}{l}\text { I want to have responsibility for the future direction of my organization } \\
\text { or business. }\end{array}$ & 3.603 & 1.004 & -0.296 & -0.456 & 0.481 \\
\hline LEA6 & Attaining leadership status in my career is not that important to me. & 2.856 & 1.094 & -0.048 & -0.576 & 0.441 \\
\hline LEA7 & $\begin{array}{l}\text { I hope to move up to a leadership position in my organization or } \\
\text { business. }\end{array}$ & 3.463 & 0.979 & -0.129 & -0.353 & 0.546 \\
\hline LEA8 & $\begin{array}{l}\text { I plan to rise to the top leadership position of my organization or } \\
\text { business. }\end{array}$ & 3.431 & 0.996 & -0.190 & -0.409 & 0.478 \\
\hline & Achievement aspirations & & & & & \\
\hline $\mathrm{ACH} 1$ & I want to be among the very best in my field. & 3.547 & 0.999 & -0.269 & -0.394 & 0.541 \\
\hline $\mathrm{ACH} 2$ & I want my work to have a lasting impact on my field. & 3.466 & 1.010 & -0.249 & & 0.571 \\
\hline $\mathrm{ACH} 3$ & I aspire to have my contributions at work recognized by my employer. & 3.576 & 0.972 & -0.327 & -0.203 & 0.633 \\
\hline $\mathrm{ACH} 4$ & Being outstanding at what I do at work is very important to me. & 3.295 & 1.001 & -0.169 & -0.288 & 0.578 \\
\hline $\mathrm{ACH} 5$ & I know that I will be recognized for my accomplishments in my field & 3.403 & 0.941 & -0.221 & -0.072 & 0.621 \\
\hline $\mathrm{ACH} 6$ & Achieving in my career is not at all important to me. & 2.561 & 1.275 & 0.209 & -1.089 & 0.230 \\
\hline $\mathrm{ACH} 7$ & I plan to obtain many promotions in my organization or business. & 3.436 & 1.014 & -0.266 & -0.243 & 0.522 \\
\hline \multirow[t]{2}{*}{$\mathrm{ACH} 8$} & Being one of the best in my field is not important to me. & 2.727 & 1.162 & -0.028 & -0.828 & 0.315 \\
\hline & Educational aspirations & & & & & \\
\hline EDU1 & I plan to reach the highest level of education in my field. & 3.510 & 1.052 & -0.203 & -0.584 & 0.710 \\
\hline EDU2 & I will pursue additional training in my occupational area of interest. & 3.595 & 0.996 & -0.331 & -0.325 & 0.756 \\
\hline EDU3 & I will always be knowledgeable about recent advances in my field. & 3.417 & 0.987 & -0.199 & -0.332 & 0.710 \\
\hline EDU4 & I know I will work to remain current regarding knowledge in my field. & 3.485 & 0.943 & -0.224 & -0.179 & 0.760 \\
\hline EDU5 & I will attend conferences annually to advance my knowledge. & 3.366 & 0.951 & -0.159 & -0.220 & 0.654 \\
\hline EDU6 & $\begin{array}{l}\text { Even if not required, I would take continuing education courses to } \\
\text { become more knowledgeable. }\end{array}$ & 3.498 & 0.975 & -0.172 & -0.350 & 0.775 \\
\hline EDU7 & $\begin{array}{l}\text { I would pursue an advanced education program to gain specialized } \\
\text { knowledge in my field. }\end{array}$ & 3.492 & 0.990 & -0.234 & -0.397 & 0.747 \\
\hline EDU8 & $\begin{array}{l}\text { Every year, I will prioritize involvement in continuing education to } \\
\text { advance my career. }\end{array}$ & 3.498 & 0.936 & -0.207 & -0.122 & 0.679 \\
\hline
\end{tabular}


Item skewness $(S K)$ ranged from -0.331 to 0.209 , and kurtosis $(K U)$ ranged from -0.072 to -1.089 ; absolute values were less than 3 for $S K$ and 10 for $K U$ [52]. These values indicated that the population data had normal distribution.

The Pearson's correlation coefficient $(r)$ measures the linear relationship on a standard scale between two variables in the CAS-R model and can represent an effect size [53] (Table 2). An absolute value of $r$ from $0.00-0.19$ indicates a very weak relationship, $0.20-0.39$ represents a weak relationship, 0.40-0.59 represents a moderate relationship, 0.60-0.79 represents a strong relationship, and 0.80-1.00 represents a very strong relationship [54]. Relatively high correlations would be good for factor analysis, but a value of 0.90 and higher may indicate a multicollinearity problem [51]. In this study, $r$ between CAS-R subscales ranged from 0.69 to 0.82 , supporting use of factor analysis [55]. Kaiser-MeyerOlkin measure sampling adequacy was $0.955(>0.60)$, and Bartlett's test of sphericity was highly significant $(p<0.05)$, indicating that factor analysis could be applied to this dataset [56,57].

\subsection{Factor Structure and Reliability}

Tables 4 and 5 describe the CFA results, including goodness-of-fit indices and standardized factor loadings $(\beta)$ for the 24-item and 18-item three-factor CAS-R models. First, tests of the 24-item three-factor model indicated an acceptable fit to the data $\left(\chi^{2}=619.215\right.$, $d f=226, p=0.000, \chi^{2} / d f=2.740, \mathrm{CFI}=0.954, \mathrm{TLI}=0.943, \mathrm{RMSEA}=0.054$ (0.049-0.059), and SRMR $=0.035)$. Values of $\beta$ ranged from 0.134 to 0.824 . Following recommendations by Hair, Black, Babin, and Anderson [51], items LEA2, LEA3, LEA4, LEA6, ACH6, and $\mathrm{ACH} 8$ were removed from the scale because $\beta$ was less than 0.5 . Subsequently, the alternative 18-item three-factor model was tested to increase measurement reliability. As Table 4 shows, the 18 -item CAS-R showed a good fit to the data $\left(\chi^{2}=244.942, d f=112\right.$, $p=0.000, \chi^{2} / d f=2.187, \mathrm{CFI}=0.981, \mathrm{TLI}=0.974, \mathrm{RMSEA}=0.045(0.037-0.052)$, and SRMR $=0.024$ ). Additionally, as Table 5 shows, the $\beta$ of the 18 -item version ranged from 0.632 to 0.815 , meeting a critical threshold value. The highest $\beta$ for leadership, achievement, and educational aspirations were LEA5 $(\beta=0.815), \operatorname{ACH} 3(\beta=0.792)$, and EDU6 $(\beta=0.798)$, respectively. In contrast, the lowest were LEA1 $(\beta=0.632)$ for leadership, $\mathrm{ACH} 4(\beta=0.661)$ for achievement, and EDU5 $(\beta=0.681)$ for educational aspirations. Overall, based on the goodness-of-fit indices and factor loadings, the three subscales explained the CAS-R latent factors well, and all of the items or measured variables could confirm and define their construct's factor structure.

Table 4. Model fit indices for the three-factor measurement model and the MIMIC model.

\begin{tabular}{|c|c|c|c|c|c|c|c|c|}
\hline Models & $\chi^{2}$ & $d f$ & $p$-Value & $\chi^{2} / d f$ & CFI & TLI & $\begin{array}{l}\text { RMSEA } \\
(95 \% \mathrm{CI})\end{array}$ & SRMR \\
\hline $\begin{array}{l}\text { 24-item three-factor } \\
\text { model }\end{array}$ & 619.215 & 226 & 0.000 & 2.740 & 0.954 & 0.943 & $\begin{array}{c}0.054 \\
(0.049-0.059)\end{array}$ & 0.035 \\
\hline $\begin{array}{l}\text { 18-item three-factor } \\
\text { model }\end{array}$ & 244.942 & 112 & 0.000 & 2.187 & 0.981 & 0.974 & $\begin{array}{c}0.045 \\
(0.037-0.052)\end{array}$ & 0.024 \\
\hline MIMIC model-18 items & 388.211 & 187 & 0.000 & 2.076 & 0.972 & 0.963 & $\begin{array}{c}0.043 \\
(0.037-0.049)\end{array}$ & 0.029 \\
\hline $\begin{array}{l}\text { MIMIC model with } \\
\text { DIF-18 items }\end{array}$ & 481.347 & 185 & 0.000 & 2.602 & 0.958 & 0.945 & $\begin{array}{c}0.052 \\
(0.046-0.058)\end{array}$ & 0.029 \\
\hline
\end{tabular}


Table 5. Standardized factor loadings of the CAS-R 24- and 18-item three-factor measurement model.

\begin{tabular}{|c|c|c|c|c|c|c|c|}
\hline \multirow{2}{*}{ Subscales } & \multirow{2}{*}{ Items } & \multicolumn{2}{|c|}{ 24-Item } & \multicolumn{4}{|c|}{ 18-Item } \\
\hline & & $\beta$ & $t$-Value & $\beta$ & $t$-Value & CR & AVE \\
\hline \multirow[t]{9}{*}{ Leadership aspirations } & & & & & & 0.833 & 0.557 \\
\hline & LEA5 & $0.824^{* *}$ & 50.732 & $0.815^{* *}$ & 47.580 & & \\
\hline & LEA7 & $0.791^{* *}$ & 42.303 & $0.798^{* *}$ & 43.777 & & \\
\hline & LEA8 & $0.709 * *$ & 32.375 & $0.726^{* *}$ & 34.399 & & \\
\hline & LEA1 & $0.637^{* *}$ & 24.583 & $0.632 * *$ & 24.055 & & \\
\hline & LEA4 & $0.338 * *$ & 8.853 & & & & \\
\hline & LEA6 & $0.214^{* *}$ & 5.211 & & & & \\
\hline & LEA2 & $0.141^{* *}$ & 3.375 & & & & \\
\hline & LEA3 & $0.134^{* *}$ & 3.186 & & & & \\
\hline \multirow[t]{9}{*}{ Achievement aspirations } & & & & & & 0.861 & 0.509 \\
\hline & $\mathrm{ACH} 3$ & $0.794^{* *}$ & 47.75 & $0.792^{* *}$ & 47.284 & & \\
\hline & $\mathrm{ACH} 5$ & $0.759 * *$ & 40.391 & $0.762 * *$ & 40.620 & & \\
\hline & $\mathrm{ACH} 1$ & $0.719 * *$ & 34.295 & $0.694^{* *}$ & 30.544 & & \\
\hline & $\mathrm{ACH} 7$ & $0.693^{* *}$ & 30.716 & $0.693^{* *}$ & 30.406 & & \\
\hline & $\mathrm{ACH} 2$ & $0.677^{* *}$ & 28.48 & $0.669^{* *}$ & 27.651 & & \\
\hline & $\mathrm{ACH} 4$ & $0.643^{* *}$ & 25.438 & $0.661^{* *}$ & 26.845 & & \\
\hline & $\mathrm{ACH} 8$ & $0.125 * *$ & 3.006 & & & & \\
\hline & $\mathrm{ACH} 6$ & 0.04 & 0.942 & & & & \\
\hline \multirow[t]{9}{*}{ Educational aspirations } & & & & & & 0.915 & 0.574 \\
\hline & EDU2 & $0.795 * *$ & 48.121 & $0.792 * *$ & 47.428 & & \\
\hline & EDU4 & $0.794^{* *}$ & 48.258 & $0.797 * *$ & 48.918 & & \\
\hline & EDU6 & $0.793 * *$ & 47.667 & $0.798^{* *}$ & 48.798 & & \\
\hline & EDU1 & $0.770 * *$ & 42.897 & $0.754^{* *}$ & 39.434 & & \\
\hline & EDU7 & $0.761^{* *}$ & 40.770 & 0.761 ** & 40.671 & & \\
\hline & EDU3 & $0.755^{* *}$ & 39.875 & $0.745^{* *}$ & 37.903 & & \\
\hline & EDU8 & $0.727^{* *}$ & 35.351 & $0.728^{* *}$ & 35.435 & & \\
\hline & EDU5 & $0.675 * *$ & 28.582 & $0.681^{* *}$ & 29.185 & & \\
\hline
\end{tabular}

Note: ${ }^{* *}=p<0.01$.

Regarding convergent validity, composite reliability for each construct was greater than the standard 0.6, and the average variance that was extracted was acceptable at 0.5 [51], indicating adequate convergent validity (Table 5). Finally, the 18-item, three-factor model, including four items for leadership, six for achievement, and eight for educational aspirations, was used to test to the MIMIC model in the next step.

Regarding internal consistency for each subscale (Table 2), Cronbach's alpha [58] was 0.761 for leadership, 0.781 for achievement, and 0.916 for educational aspirations. According to Nunnally's recommendation [59], the scales achieved adequate reliability and could be used to measure the CAS-R with confidence. To test the scale's homogeneity and the unidimensionality of the items, corrected item-total correlations (CITC) [60] ranged from 0.230 to 0.775 (Table 3). Based on the CITC rule of thumb of 0.2 or 0.3 [61,62], we can reasonably conclude that all of the items were good and belonged to the questionnaire.

\subsection{MIMIC Model}

The results of the MIMIC model are divided into two parts: MIMIC model without DIF and MIMIC model with DIF. In Figures 3 and 4, the ellipses (green) represent the latent factors, and the rectangles represent the covariate (yellow) and items (white). The solid and dotted lines with a single-headed arrow point from the covariates to the latent factors, and the items represent regression paths or the impact of the predictors on the latent factors and items. The single-headed arrows pointing from the latent factors to each item represent standardized factor loadings. 
Covariates $(X)$

Latent Constructs ( $\eta$ )

$\underline{\operatorname{Items}(\mathrm{Y})}$ (CAS-R subscales)

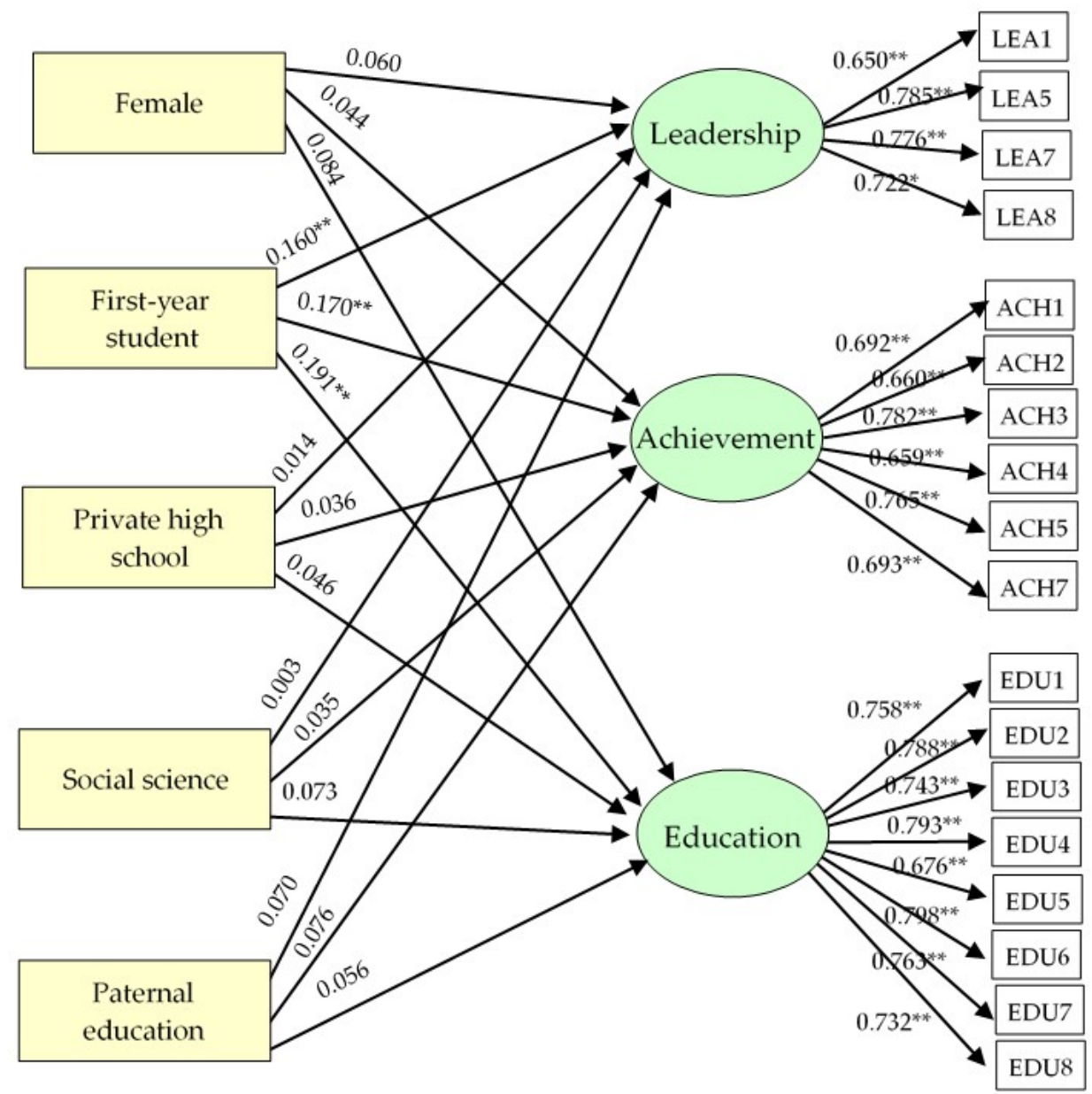

Figure 3. MIMIC model without DIF. Note: ${ }^{*}=p<0.05 ;{ }^{*}=p<0.01$. 
$\underline{\text { Covariates }(X)}$

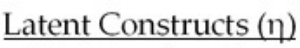

$\underline{\text { Items (Y) }}$ (CAS-R subscales)

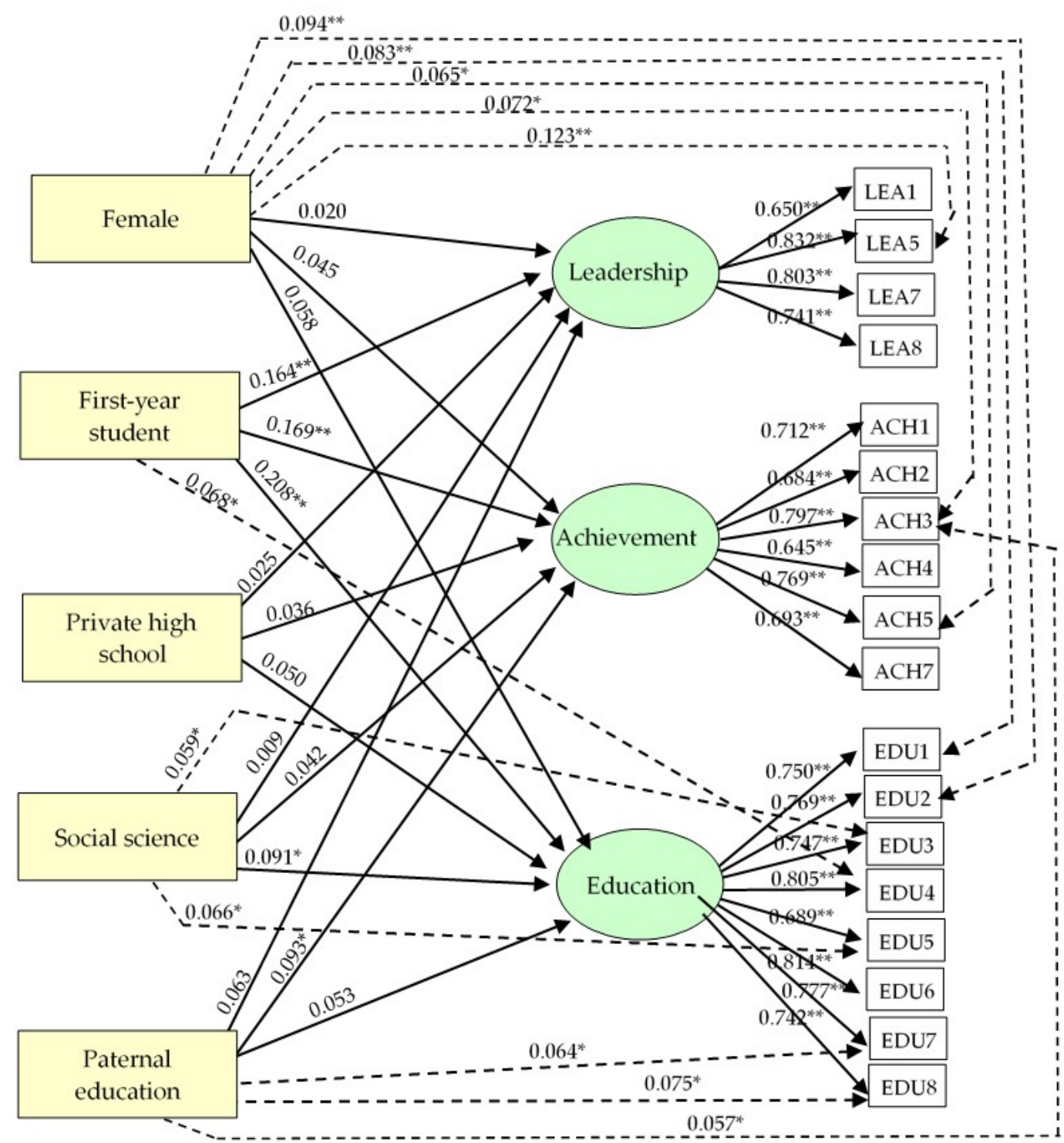

Figure 4. MIMIC model with DIF. Note: ${ }^{*}=p<0.05 ;{ }^{* *}=p<0.01$.

\subsubsection{MIMIC Model without DIF}

The MIMIC model was run on the 18-item CAS-R, in which gender, year of study, type of high school, major, and paternal education predicted the three latent factors. Overall, the model adequately fit the data $\left(\chi^{2}(187)=388.211, p<0.001, \chi^{2} / d f=2.076, \mathrm{CFI}=0.972\right.$, $\mathrm{TLI}=0.963, \mathrm{SRMR}=0.029$, and RMSEA $=0.043(95 \% \mathrm{CI}=0.037-0.052))($ Table 4$)$. The standardized effects on the three latent factors are reported in Table 6 and Figure 3. All of the measured factor loadings remained strong and statistically significant. As shown in Figure 3, only year of study (first-year student) had a positive direct effect on leadership $(\beta=0.160, p<0.01)$, achievement $(\beta=0.170, p<0.01)$, and educational aspirations $(\beta=0.191$, $p<0.01$ ). This means that first-year students had $0.160 S D, 0.170 S D$, and $0.191 S D$ higher latent mean scores than other students for leadership, achievement, and educational aspirations, respectively. These concluded that first-year students had a higher probability of leadership, achievement, and educational aspirations than other students. By contrast, gender (for leadership $-\beta=0.060, p>0.05$; for achievement $-\beta=0.044, p>0.05$; for 
education $-\beta=0.084, p>0.05$ ), type of high school (for leadership $-\beta=0.014, p>0.05$; for achievement $-\beta=0.036, p>0.05$; for education $-\beta=0.046, p>0.05$ ), major (for leadership$\beta=0.003, p>0.05$; for achievement $-\beta=0.035, p>0.05$; for education $-\beta=0.073, p>0.05$ ), and paternal education (for leadership $-\beta=0.070, p>0.05$; for achievement $-\beta=0.076$, $p>0.05$; for education $-\beta=0.056, p>0.05$ ) were not statistically significant, indicating that leadership, achievement, and educational aspirations show no differences between gender, type of high school, major, and paternal education. The four sociodemographic covariates could explain the variance of the three latent factors as follows: leadership aspirations = $3.3 \%\left(R^{2}=0.033\right)$, achievement aspirations $=3.9 \%\left(R^{2}=0.039\right)$, and educational aspirations $=5.6 \%\left(R^{2}=0.056\right)$.

Table 6. Impact of covariates on three subscales and items.

\begin{tabular}{|c|c|c|c|c|c|c|c|c|c|c|c|c|}
\hline \multirow{3}{*}{ Covariates/Predictors } & \multicolumn{6}{|c|}{ MIMIC Model } & \multicolumn{6}{|c|}{ MIMIC Model with DIF } \\
\hline & \multicolumn{2}{|c|}{ Leadership } & \multicolumn{2}{|c|}{ Achievement } & \multicolumn{2}{|c|}{ Education } & \multicolumn{2}{|c|}{ Leadership } & \multicolumn{2}{|c|}{ Achievement } & \multicolumn{2}{|c|}{ Education } \\
\hline & $\beta$ & $t$-Value & $\beta$ & $t$-Value & $\beta$ & $t$-Value & $\beta$ & $t$-Value & $\beta$ & $t$-Value & $\beta$ & $t$-Value \\
\hline Female & 0.060 & 1.299 & 0.044 & 0.967 & 0.084 & 1.923 & 0.020 & 0.416 & 0.045 & 0.962 & 0.058 & 1.307 \\
\hline First-year student & $0.160 * *$ & 3.644 & $0.170^{* *}$ & 3.912 & 0.191 ** & 4.596 & $0.164 * *$ & 3.902 & $0.169 * *$ & 3.944 & $0.208 * *$ & 4.997 \\
\hline Private high school & 0.014 & 0.323 & 0.036 & 0.806 & 0.046 & 1.083 & 0.025 & 0.580 & 0.036 & 0.832 & 0.050 & 1.195 \\
\hline Social science & 0.003 & 0.057 & 0.035 & 0.763 & 0.073 & 1.633 & 0.009 & 0.195 & 0.042 & 0.916 & 0.091 & $2.048 *$ \\
\hline \multirow[t]{2}{*}{ Paternal education } & 0.070 & 1.571 & 0.076 & 1.718 & 0.056 & 1.308 & 0.063 & 1.469 & 0.093 & $2.103^{*}$ & 0.053 & 1.245 \\
\hline & & & & & & & $\beta$ & $t$-value & & & & \\
\hline Female $\longrightarrow$ LEA5 & & & & & & & $0.123 * *$ & 3.718 & & & & \\
\hline Female $\longrightarrow$ ACH3 & & & & & & & $0.072 *$ & 2.422 & & & & \\
\hline Female $\rightarrow$ ACH5 & & & & & & & $0.065 *$ & -2.092 & & & & \\
\hline Female $\longrightarrow$ EDU1 & & & & & & & $0.083^{* *}$ & 2.864 & & & & \\
\hline Female $\rightarrow$ EDU2 & & & & & & & $0.094^{* *}$ & 3.483 & & & & \\
\hline First-year student $\rightarrow$ E & & & & & & & $0.068^{*}$ & -2.446 & & & & \\
\hline Social science $\rightarrow$ EDU3 & & & & & & & $0.059 *$ & -2.076 & & & & \\
\hline Social science $\rightarrow$ EDU5 & & & & & & & $0.066^{*}$ & -2.067 & & & & \\
\hline Paternal education $\rightarrow$ & CH3 & & & & & & $0.057^{*}$ & -2.019 & & & & \\
\hline Paternal education $\rightarrow$ & U7 & & & & & & $0.064^{*}$ & 2.293 & & & & \\
\hline Paternal education $\rightarrow$ & U8 & & & & & & $0.075^{*}$ & -2.532 & & & & \\
\hline
\end{tabular}

Note: ${ }^{*}=p<0.05 ; * *=0.01$.

\subsubsection{MIMIC Model with DIF}

To test the MIMIC model with DIF, the direct effect from covariates to items of the CAS-R was freely estimated. As shown in Table 6 and Figure 4 , the MIMIC model with DIF demonstrated a good fit to the data $\left(\chi^{2}(185)=481.347, p<0.001 \chi^{2} / d f=2.602, \mathrm{CFI}=0.958\right.$, $\mathrm{TLI}=0.945$, SRMR $=0.029$, and RMSEA $=0.052(95 \% \mathrm{CI}=0.046-0.058))$. In particular, results showed that female students were more likely to report higher scores than males on five items, namely LEA5 $(\beta=0.123, p<0.01)$, ACH3 $(\beta=0.072, p<0.05)$, ACH5 ( $\beta=0.065$, $p<0.05)$, EDU1 $(\beta=0.083, p<0.01)$, and EDU2 $(\beta=0.094, p<0.01)$. First-year students had greater probability than others to possess EDU4 $(\beta=0.068, p<0.05)$, and social science students were likely to report higher scores than others on EDU3 $(\beta=0.059, p<0.05)$ and EDU5 $(\beta=0.066, p<0.05)$. Students whose fathers held a bachelor's degree or higher tended to greater aspiration in $\mathrm{ACH} 3(\beta=0.057, p<0.05)$, EDU7 $(\beta=0.064, p<0.05)$, and EDU8 $(\beta=0.075, p<0.05)$.

Adjusting the MIMIC model for the DIF effect revealed that the standardized regression coefficients of significant covariates on the three latent factors were identical to the MIMIC model without DIF- only year of study (first-year student) had an effect on leadership $(\beta=0.164, p<0.01)$, achievement $(\beta=0.169, p<0.01)$, and educational aspirations $(\beta=0.208, p<0.01)$ (Table 6 , Figures 3 and 4$)$. This means that based on the adjusted MIMIC model, leadership, achievement, and educational aspirations were not invariant between different year students. The results led to the conclusion that standardized unit increases in the leadership, achievement, and educational aspirations are associated with 0.164, 0.169, and 0.208 standardized score increases in the first-year students, respectively. Moreover, the results showed that major (social science) affects educational aspirations ( $\beta=0.091$, $p<0.05$ ) and that paternal education (bachelor's degree or higher) affects achievement aspirations $(\beta=0.093, p<0.05)$, indicating that social science students and students whose 
fathers hold a bachelor's degree or higher have a higher probability of educational and achievement aspirations, respectively. Gender $(p>0.05)$ and type of high school $(p>0.05)$ do not lead to differences in the three latent factors of the CAS-R. These covariates could explain the variance between the latent factors as follows: leadership aspirations $=3.1 \%$ $\left(R^{2}=0.031\right)$, achievement aspirations $=4.3 \%\left(R^{2}=0.043\right)$, and educational aspirations $=$ $6.2 \%\left(R^{2}=0.062\right)$. In comparing the regression coefficients of the covariates with the latent factor and $R^{2}$ between the MIMIC models with and without DIF, the very small changes in the regression coefficient and $R^{2}$ did not contaminate the relationship pattern between the five sociodemographic covariates and the three latent factors.

\section{Discussion}

\subsection{The Factor Structure of the CAS-R}

This study examined the factor structure of the CAS-R, which has been used in psychology, education, and social science research to investigate the desire for professional promotion, higher education, and expertise in student career paths. The findings add evidence to previous research by using a MIMIC model with and without DIF and by providing the influence of sociodemographic factors as covariates on the CAS. The study replicated the original 24-item CAS's three-factor structure in a sample of college students in rural Thailand. Because six items (LEA4, LEA6, LEA2, LEA3, ACH8, and ACH6) of the original version were found to have low reliability, they were removed. Therefore, the CFA results supported the use of the three-factor structure for the 18-item CAS-R because its items well represented the latent factors, and an instrument is represented by the reliability and validity of its measures [63,64]. This is consistent with Gregor, Pino, Gonzalez, Soto, and Dunn [23], in which only the achievement and education subscales showed sufficient reliability with undergraduate students from the United States. These results are also similar to those of Kim, O'Brien, and Kim [30], who reported that the 18-item three-factor CAS-R model had better fit than the 24-item version when tested with female college students in South Korea. Additionally, a three-factor model can represent the CAS-R better than a single-factor model [30]. Differences in the number of items and factors across studies may be due to different sample background characteristics, cultural and linguistic differences, question-wording, the meanings of items, and measurement methods [65-68].

For the 18-item CAS-R, Cronbach's alpha coefficient values were high for all three subscales, which is consistent with previous results indicating their good reliability. Additionally, in Kim, O'Brien, and Kim's similar findings [30], the CAS-R showed good internal consistency. In contrast, Gregor, Pino, Gonzalez, Soto, and Dunn [23] found that only the achievement and education subscales showed sufficient reliability when employed with U.S. undergraduates, whereas all of the items loaded significantly on the three subscales. Item LEA5 (I want to have responsibility for the future direction of my organization or business, $\beta=0.815$ ), item ACH3 (I aspire to have my contributions at work recognized by my employer, $\beta=0.792$ ), and item EDU6 (Even if not required, I would take continuing education courses to become more knowledgeable, $\beta=0.798$ ) showed the highest loadings among leadership, achievement, and educational aspirations, respectively. This result implies that rural college students in Thailand placed their highest priority on the future direction of their career, their performance in accordance with employer requirements, and the continual development of their competence. These findings differ from those of a Korean study in which students placed the highest priority on organizational leadership, working with long-term effects in the field, and obtaining an advanced education [30]. They are also inconsistent with Khampirat's study [13], which found that female Thai students prioritized organizational leadership, success in the field, and monitoring the progress of knowledge in the field. In this study, however, differences in the effects of sociodemographic characteristics on the three subscales were generally small, and other factors may have caused variations in the scales. 


\subsection{Covariates' Effect on the Three Subscales of CAS-R and DIF}

Results showed that the MIMIC model with DIF had a good fit to the empirical data and was similar to the results of the without DIF model. DIF did not change the direction of association between the covariates and the leadership, achievement, and education scores. In the DIF model, only first-year students had a statistically significant effect on the three latent subscales. The greatest path coefficient size was found in the positive effect of being a first-year student on educational aspiration, followed by achievement and leadership aspirations, respectively. Interestingly, gender, type of high school, major, and paternal education showed nonsignificant effects on the three CAS-R subscales. Perhaps because of the importance of aspirations influencing future success, these results also reinforce the individual equivalence of the three-factor model.

The MIMIC model with DIF indicated that gender, year of study, major, and paternal education caused inequality in some CAS-R items. Gender was a source of measurement variance (DIF) for five items (LEA5, ACH3, ACH5, EDU1, and EDU2) in the three subscales. This implies that females were more likely than males to possess these characteristics. Gender was the most associated with differences in scores for the leadership subscale item LEA5 (I want to have responsibility for the future direction of my organization or business) and for the educational subscale item EDU2 (I will pursue additional training in my occupational area of interest). Similar to the findings of Feliciano and Rumbaut [69] and Nadeem and Khalid [36], these results suggest gender differences in career aspiration: compared to males, females exhibited higher career aspirations. However, other researchers have demonstrated gender equality in career aspirations and expectations.

Paternal education level caused the most variation in educational subscale items EDU8 (Every year, I will prioritize involvement in continuing education to advance my career) and EDU7 (I would pursue an advanced education program to gain specialized knowledge in my field), followed by the achievement subscale item ACH3 (I aspire to have my contributions at work recognized by my employer). This result aligns with the finding by Al-Bahrani, Allawati, Abu Shindi, and Bakkar [2] that in the Sultanate of Oman, students whose fathers had university degrees reported significantly stronger aspirations than those whose fathers were literate, with a high school diploma or below. This is also consistent with prior research by Hill et al. [70], who found that most students with university-educated parents intended to complete higher education courses. This study also relates to literature on aspiration gaps [71], in that several studies [72-79] have found students from disadvantaged parents (e.g., low educational levels, working-class) to have lower career aspirations and fewer further educational choices than those whose parents had higher socioeconomic status.

In addition, in educational subscale items EDU3 (I will always be knowledgeable about recent advances in my field) and EDU5 (I will attend conferences annually to advance my knowledge), this study found that social science students had higher scores than students in other majors. At some point, perhaps socialization mechanisms and rational choice motivations impact the different aspirations of students [80] because during college years, students realistically assess their aspirations and develop an understanding of their future career needs [81,82]. Similar to responses to item EDU4 (I know I will work to remain current regarding knowledge in my field), first-year students rated themselves higher than other-year students. This is possibly because first-year students want to reach a level of high achievement in their majors. As Gutman and Akerman [83] said, adolescents who believe that they have the ability to succeed and who consider success to come through hard work have higher aspirations than their peers.

The MIMIC model's application allowed researchers to show that sociodemographic background affects the leadership, achievement, and education subscales. These findings suggest that recognizing the impact of sociodemographic background on CAS-R and the aspirations of first year students during the transition to higher education institutions (HEIs) is necessary to understand their career aspirations and to develop a model to prepare them properly for the work [84]. Although students have high career aspirations 
and clear goals, HEIs should provide appropriate career guidance and motivation so that students can achieve long-term success [85].

\section{Conclusions}

This study's approach produced groundbreaking findings in career education. In particular, the applied MIMIC model indicated that first-year students had a statistically significant impact on CAS-R, and DIF analysis revealed that gender (female), year of study (first-year students), major (social science), and paternal education (bachelor's degree and higher) could have caused gaps in 10 items. That is, female students are more ambitious than males for LEA5, ACH3, ACH5, EDU1, and EDU2. First-year students are more aware than other years in EDU4. Social science students reported stronger aspirations than other majors in EDU3 and EDU5. Students whose fathers had university degrees were more ambitious than those whose fathers had lower levels of education in ACH3, EDU7, and EDU8.

The results also provide a greater understanding of the effect of the backgrounds of rural Thai college students on their career aspirations. In general, student career aspirations are shaped by gender, social class, and sociodemographic background [15,19]. For example, the students of fathers who have higher education degrees are likely to have a much higher aspiration for pursuing an advanced education program than peers from different backgrounds [19]. For rural Thai college students, previous the studies of Khampirat [7] and Deveney [86] showed that there is a difference in the career aspirations between students from disadvantaged socio-economic backgrounds and their more advantaged peers. In addition, this study revealed that students placed their highest priority on the direction of their future career, their performance in accordance with employer requirements, and the continual development of their competence.

Based on these findings, educators, practitioners, or policymaker who are involved in students development programs in educational institutions could use the validated CAS-R model as an instrument to monitor student aspirations and to prepare themselves for employability by defining and planning their career choices at different life stages [87]. Moreover, information about CAS-R measurement would be useful for researchers, practitioners, and career counselors interested in helping college students develop career choices and aspirations, especially during the current global COVID-19 outbreak that has sparked a major economic and job crisis [88]. Finally, study findings on the CAS-R model's fit to the data and the occurrence of the MIMIC model with and without DIF should be tested for generalizability with other populations.

This research provides theoretical and practical implications that contribute to the topic under study. First, although from the theoretical point of view, the concept of CAS-R covers all important aspects of career aspirations and has been proven to be suitable for the Thai students studied in this work; the next step of the development is to provide predictive validity on relevant attributes, such as student employability, career-field choice, vocational identity, and the future of their work. Second, because this study aims to connect sociodemographic backgrounds with career aspirations, the results and suggestions are beneficial for educators, practitioners, or policymakers who focus on developing student career aspirations based on their individual backgrounds. In this respect, the use of the CAS-R can help measure motivations and ambitions at different stages of student life. Third, in the current context, in which COVID-19 affects student career development anxiety [89], self-training to have work-ready expertise and skills is essential $[7,89,90]$, and the CAS-R can be a valuable option to assess one's aspirations. Students could obtain information to monitor their expectations, increase career aspirations, and improve essential competencies for their future jobs.

In future work, MIMIC model validation should be made between different student culture groups, e.g., urban and rural students, indigenous and non-indigenous people, students from socially disadvantaged and general groups, or between different regions. These studies will ensure that the comparison of the mean factors is reasonable and 
meaningful. Furthermore, to seek a better understanding of the phenomenon under study through the description, qualitative research approaches based on the different experiences and insights of students could complement the information obtained in this research.

\section{Limitations}

One limitation of this study was that the sample came from only three rural community colleges in Thailand's central region. To obtain more comprehensive findings and to increase research validity, further research should include additional HEIs in other regions. In addition, this was a cross-sectional study. In the future, longitudinal studies should be conducted to explore how much student career aspirations change over time or from student life to working life. Additionally, this study only tested the impact of certain group variables on the CAS-R. For more diverse perspectives, further studies should discover-during a pandemic and in a digital society-how career aspirations relate to career counseling, social media use, and remote learning by applying structural equation models.

Author Contributions: Conceptualization, J.K. and B.K.; methodology, J.K. and B.K.; software, B.K.; validation, J.K. and B.K.; formal analysis, J.K., D.C. and B.K.; investigation, J.K.; resources, J.K. and B.K.; data curation, J.K. and B.K.; writing-original draft preparation, J.K., D.C. and B.K.; writingreview and editing, B.K.; visualization, J.K., D.C. and B.K.; supervision, B.K.; project administration, J.K. and B.K.; funding acquisition, B.K. All authors have read and agreed to the published version of the manuscript.

Funding: This research was funded by the National Research Council of Thailand (NRCT) and the Suranaree University of Technology (SUT) (grant number NRCT5-RSA63009-02) and was supported by the Suranaree University of Technology Research and Development Fund (grant number IRD2202-64-12-12). The APC was funded by SUT.

Institutional Review Board Statement: The study was conducted according to the guidelines of the Declaration of Helsinki, and approved by the Institutional Review Board (or Ethics Committee) of Suranaree University of Technology (protocol code EC-63-0017, 4 May 2020).

Informed Consent Statement: Not applicable.

Data Availability Statement: Data are available upon request due to privacy restrictions.

Acknowledgments: The authors would like to acknowledge Karen M. O'Brien for allowing us to use the CAS-R questionnaire. The authors also thank Duangjai Boonkusol, Santikorn Pinyong, and Panuwat Hoonpong for supporting the data collection.

Conflicts of Interest: The authors declare no conflict of interest. The funders had no role in the design of the study; in the collection, analyses, or interpretation of data; in the writing of the manuscript; or in the decision to publish the results.

\section{References}

1. Patton, W.; Creed, P. The Relationship Between Career Variables and Occupational Aspirations and Expectations for Australian High School Adolescents. J. Career Dev. 2007, 34, 127-148. [CrossRef]

2. Al-Bahrani, M.A.; Allawati, S.M.; Abu Shindi, Y.A.; Bakkar, B.S. Career aspiration and related contextual variables. Int. J. Adolesc. Youth 2020, 25, 703-711. [CrossRef]

3. Rojewski, J.W. Occupational aspirations: Constructs, meaning and application. In Career Development and Counselling: Putting Theory and Research to Work; Brown, S.D., Lent, R.W., Eds.; John Wiley \& Sons: Hoboken, NJ, USA, 2005; pp. 131-154.

4. Sewell, W.H.; Haller, A.O.; Portes, A. The Educational and Early Occupational Attainment Process. Am. Sociol. Rev. 1969, $34,82$. [CrossRef]

5. Gottfredson, L.S. Applying Gottfredson's theory of circumscription and compromise in career guidance and counseling. In Career Development and Counseling: Putting Theory and Research to Work; Brown, S.D., Lent, R.W., Eds.; John Wiley \& Sons: Hoboken, NJ, USA, 2005; pp. 71-100.

6. Rogers, M.E.; Creed, P.; Glendon, A.I. The role of personality in adolescent career planning and exploration: A social cognitive perspective. J. Vocat. Behav. 2008, 73, 132-142. [CrossRef]

7. Khampirat, B. The relationship between paternal education, self-esteem, resilience, future orientation, and career aspirations. PLoS ONE 2020, 15, e0243283. [CrossRef] [PubMed] 
8. Akkermans, J.; Richardson, J.; Kraimer, M.L. The Covid-19 crisis as a career shock: Implications for careers and vocational behavior. J. Vocat. Behav. 2020, 119, 103434. [CrossRef]

9. Nielsen, K. "Fake It 'til You Make It": Why community college students' aspirations "hold steady". Sociol. Educ. 2015, 88, 265-283. [CrossRef]

10. Swanson, J.L.; Tokar, D.M. College students' perceptions of barriers to career development. J. Vocat. Behav. 1991, 38, 92-106. [CrossRef]

11. Lent, R.W.; Brown, S.D.; Talleyrand, R.; McPartland, E.B.; Davis, T.; Chopra, S.B.; Alexander, M.S.; Suthakaran, V.; Chai, C.-M. Career Choice Barriers, Supports, and Coping Strategies: College Students' Experiences. J. Vocat. Behav. 2002, 60, 61-72. [CrossRef]

12. Tang, M.; Pan, W.; Newmeyer, M.D. Factors Influencing High School Students' Career Aspirations. Prof. Sch. Couns. 2008, 11, 285-295. [CrossRef]

13. Khampirat, B. A Second-Order Confirmatory Factor Analysis of the Career Aspirations Scale of Female Thai Students. Int. J. Learn. Teach. Educ. Res. 2019, 18, 265-282. [CrossRef]

14. Weeranakint, W.; Sungsanit, M. The Relations between work-family conflict, self-efficacy, social support, and career aspirations of women in managerial positions, in Nakhorn Ratchasima Province. Suranaree J. Soc. Sci. 2009, 3, 91-108.

15. Ulrich, A.; Helker, K.; Losekamm, K. “What Can I Be When I Grow Up?"-The Influence of Own and Others' Career Expectations on Adolescents' Perception of Stress in Their Career Orientation Phase. Sustainability 2021, 13, 912. [CrossRef]

16. Powell, L.; Amsbary, J.; Hickson, M. The Wai in Thai culture: Greeting, status-marking and national identity functions. J. Intercult. Commun. 2014, 34, 7.

17. Reyes, O.; Kobus, K.; Gillock, K. Career Aspirations of Urban, Mexican American Adolescent Females. Hisp. J. Behav. Sci. 1999, 21, 366-382. [CrossRef]

18. Fouad, N.A.; Byars-Winston, A. Cultural Context of Career Choice: Meta-Analysis of Race/Ethnicity Differences. Career Dev. $Q$. 2005, 53, 223-233. [CrossRef]

19. Owusu, M.K.; Owusu, A.; Fiorgbor, E.T.; Atakora, J. Career Aspiration of Students: The Influence of Peers, Teachers and Parents. J. Educ. Soc. Behav. Sci. 2021, 34, 67-79. [CrossRef]

20. Sapra, J.; Chaudhary, M.; Jeswal, R. A study on career aspirations and its relationship with the academic performance of undergraduate management students: Are they realistic. Int. J. Educ. Econ. Dev. 2021, 12, 253. [CrossRef]

21. Ampaire, A.; Kajumba, M.M.; Muwagga, A. Do students' career aspirations predict their career choices? A qualitative survey of advanced level secondary school students in Uganda. Afr. J. Educ. Sci. Technol. 2021, 6, 344-351.

22. Cairns, D.; Dickson, M. Exploring the Relations of Gender, Science Dispositions and Science Achievement on STEM Career Aspirations for Adolescents in Public Schools in the UAE. Asia-Pac. Educ. Res. 2021, 30, 153-165. [CrossRef]

23. Gregor, M.A.; Del Pino, H.V.G.; Gonzalez, A.; Soto, S.; Dunn, M.G. Understanding the Career Aspirations of Diverse Community College Students. J. Career Assess. 2019, 28, 202-218. [CrossRef]

24. Arbona, C.; Novy, D.M. Career Aspirations and Expectations of Black, Mexican American, and White Students. Career Dev. Q. 1991, 39, 231-239. [CrossRef]

25. Metz, A.; Fouad, N.; Ihle-Helledy, K. Career Aspirations and Expectations of College Students: Demographic and labor market comparisons. J. Career Assess. 2008, 17, 155-171. [CrossRef]

26. Whose culture has capital? A critical race theory discussion of community cultural wealth. Race Ethn. Educ. 2005, 8, 69-91. [CrossRef]

27. O'Brien, K.M. The Influence of Psychological Separation and Parental Attachment on the Career Development of Adolescent Women. J. Vocat. Behav. 1996, 48, 257-274. [CrossRef]

28. Gregor, M.A.; O’Brien, K.M. Understanding Career Aspirations Among Young Women: Improving instrumentation. J. Career Assess. 2016, 24, 559-572. [CrossRef]

29. Cheng, S.; Yuen, M. Education and career aspirations among Chinese high school students: Validation of the career aspiration scale. Asia-Pac. Educ. Res. 2012, 21, 394-401.

30. Kim, Y.H.; O'Brien, K.M.; Kim, H. Measuring Career Aspirations Across Cultures: Using the career aspiration scale with young Korean women. J. Career Assess. 2016, 24, 573-585. [CrossRef]

31. Lee, H.J. The mediating effects of academic self-efficacy on the relationship between perceived career barriers and career aspiration. J. Res. Educ. 2014, 27, 1-28.

32. Sawitri, D.R.; Creed, P. Perceived career congruence between adolescents and their parents as a moderator between goal orientation and career aspirations: A social cognitive perspective. Pers. Individ. Differ. 2015, 81, 29-34. [CrossRef]

33. Sawitri, D.R.; Creed, P.A. Collectivism and Perceived Congruence With Parents as Antecedents to Career Aspirations. J. Career Dev. 2017, 44, 530-543. [CrossRef]

34. Gregor, M.; O’Brien, K.M.; Sauber, E. Understanding Career Aspirations Among Young Men. J. Career Assess. 2019, $27,262-272$. [CrossRef]

35. Tovar-Murray, D.; Parries, M.M.; Gutheil, J.; Carpenter, R. Sociodemographics, Beliefs, and Attitudes as Determinants of College Students' Career Aspirations. Career Dev. Q. 2021, 69, 114-129. [CrossRef]

36. Nadeem, F.; Khalid, R. The relationship of gender role attitudes with career aspirations and career choices among young adults. Pak. J. Psychol. Res. 2018, 33, 455-471.

37. Dar, I.A. Influence of academic streams on career aspirations of Kashmiri adolescents. Int. J. Indian Psychol. 2019, 7, 38-45. 
38. Shashwati, S. Womanhood \& work: Could sexism influence career aspirations? Int. J. Basic Appl. Res. 2019, 9, $162-167$.

39. Kumar, S.; González, O.R.G. A program-based comparative study of enjoyment of mathematics lessons and career aspirations of upper secondary students under math-science and math-english programs according to their career fields in Assumption College, Bangrak, Thailand. Sch. Hum. Sci. 2021, 13, 44-58.

40. Huang, Q.; Teng, F.; Yang, W. Awareness of societal emphasis on appearance decreases women's (but not men's) career aspiration: A serial mediation model. Scand. J. Psychol. 2021, 62, 564-573. [CrossRef]

41. Wang, W.-C.; Shih, C.-L.; Yang, C.-C. The MIMIC Method With Scale Purification for Detecting Differential Item Functioning. Educ. Psychol. Meas. 2009, 69, 713-731. [CrossRef]

42. Nielsen, J.; Levy, J. Measuring usability: Preference vs. performance. Commun. ACM 1994, 37, 66-75. [CrossRef]

43. Cohen, J.; Cohen, P.; West, S.G.; Aiken, L.S. Applied Multiple Regression/Correlation Analysis for the Behavioral Sciences; Lawrence Erlbaum Associates: Mahwah, NJ, USA, 2003; pp. xxviii, 703-xxviii, 703.

44. Jöreskog, K.G.; Goldberger, A.S. Estimation of a Model with Multiple Indicators and Multiple Causes of a Single Latent Variable. J. Am. Stat. Assoc. 1975, 70, 631-639. [CrossRef]

45. Chen, C.-F. The EM Approach to the Multiple Indicators and Multiple Causes Model via the Estimation of the Latent Variable. J. Am. Stat. Assoc. 1981, 76, 704-708. [CrossRef]

46. Holland, P.W.; Wainer, H. Differential Item Functioning; Lawrence Erlbaum: Hillsdale, NJ, USA, 1993.

47. Muthén, B. A Method for Studying the Homogeneity of Test Items with Respect to Other Relevant Variables. J. Educ. Stat. 1985, 10, 121-132. [CrossRef]

48. Finch, H. The MIMIC Model as a Method for Detecting DIF: Comparison With Mantel-Haenszel, SIBTEST, and the IRT Likelihood Ratio. Appl. Psychol. Meas. 2005, 29, 278-295. [CrossRef]

49. Wang, W.-C.; Shih, C.-L. MIMIC Methods for Assessing Differential Item Functioning in Polytomous Items. Appl. Psychol. Meas. 2010, 34, 166-180. [CrossRef]

50. Brown, T.A. Confirmatory Factor Analysis for Applied Research; Guilford Publications: New York, NY, USA, 2015; pp. xvii, 462-xvii.

51. Hair, J.J.F.; Black, W.C.; Babin, B.J.; Anderson, R.E. Multivariate Data Analysis, 7th ed.; Pearson: Essex, UK, 2014.

52. Kline, R.B. Principles and Practice of Structural Equation Modeling; Guilford Press: New York, NY, USA, 2011.

53. Cohen, J. Statistical Power and Analysis for the Behavioral Sciences; Lawrence Erlbaum Associates: Hillsdale, NJ, USA, 1988; Volume 2.

54. Evans, J.D. Straightforward Statistics for the Behavioral Sciences; Brooks/Cole Publishing: Pacific Grove, CA, USA, 1996.

55. Munro, B.H. Statistical Methods for Health Care Research; Lippincott Williams \& Wilkins: Philadelphia, PA, USA, 2005.

56. Kaiser, H.F. An index of factorial simplicity. Psychometrika 1974, 39, 31-36. [CrossRef]

57. DeVellis, R.F. Scale Development: Theory and Applications, 4th ed.; Sage Publications: Thousand Oaks, CA, USA, 2017 ; p. 121.

58. Cronbach, L.J. Coefficient alpha and the internal structure of tests. Psychometrika 1951, 16, 297-334. [CrossRef]

59. Nunnally, J.C.; Bernstein, I.H. Psychometric Theory, 3rd ed.; McGraw-Hill: New York, NY, USA, 1994.

60. Pop, C.; Khampirat, B. Self-assessment instrument to measure the competencies of Namibian graduates: Testing of validity and reliability. Stud. Educ. Eval. 2019, 60, 130-139. [CrossRef]

61. Field, A. Discovering Statistics Using SPSS; Sage: London, UK, 2005.

62. Everitt, B.S. The Cambridge Dictionary of Statistics, 2nd ed.; Cambridge University Press: Cambridge, UK, 2002.

63. Cortina, J.M. What is coefficient alpha? An examination of theory and applications. J. Appl. Psychol. 1993, 78, 98-104. [CrossRef]

64. Bagozzi, R.P.; Yi, Y.; Phillips, L.W. Assessing Construct Validity in Organizational Research. Adm. Sci. Q. 1991, 36, 421-458. [CrossRef]

65. Byrne, B.M. Testing for equivalent self-concept measurement across culture: Issues, caveats, and application. In International Advances in Self-Research: Speaking to the Future; Marsh, H.W., Craven, R.G., McInerney, D.M., Eds.; Information Age: Greenwich, CT, USA, 2003; pp. 291-314.

66. Harkness, J.; Pennell, B.-E.; Schoua-Glusberg, A. Survey questionnaire translation and assessment. In Methods for Testing and Evaluating Survey Questionnaires; Presser, S., Rothgeb, J.M., Couper, M.P., Lessler, J.T., Martin, E., Martin, J., Singer, E., Eds.; John Wiley \& Sons: Hoboken, NJ, USA, 2004; pp. 453-473. [CrossRef]

67. van de Vijver, F.; Tanzer, N. Bias and equivalence in cross-cultural assessment: An overview. Eur. Rev. Appl. Psychol. 2004, 54, 119-135. [CrossRef]

68. Khampirat, B. Validation of Motivated Strategies for Learning Questionnaire: Comparison of Three Competing Models. Int. J. Instr. 2021, 14, 609-626. [CrossRef]

69. Feliciano, C.; Rumbaut, R.G. Gendered paths: Educational and occupational expectations and outcomes among adult children of immigrants. Ethn. Racial Stud. 2005, 28, 1087-1118. [CrossRef]

70. Hill, N.E.; Castellino, D.R.; Lansford, J.E.; Nowlin, P.; Dodge, K.A.; Bates, J.E.; Pettit, G.S. Parent Academic Involvement as Related to School Behavior, Achievement, and Aspirations: Demographic Variations Across Adolescence. Child Dev. 2004, 75, 1491-1509. [CrossRef]

71. Ray, D. Aspirations, poverty and economic change. In Understanding Poverty; Banerjee, A., Benabou, R., Mookherjee, D., Eds.; Oxford University: New York, NY, USA, 2003; pp. 409-420. 
72. Ray, M.W.; Garavalia, L.S.; Gredler, M.E. Gender differences in self-regulated learning, task value, and achievement in developmental college students. In Proceedings of the Annual Meeting of the American Educational Research Association, Chicago, IL, USA, 21-25 April 2003.

73. Marjoribanks, K. Family Background, Individual and Environmental Influences, Aspirations and Young Adults' Educational Attainment: A follow-up study. Educ. Stud. 2003, 29, 233-242. [CrossRef]

74. Khattab, N. Students' aspirations, expectations and school achievement: What really matters? Br. Educ. Res. J. 2015, 41, 731-748. [CrossRef]

75. Rizzica, L. Raising Aspirations and Higher Education: Evidence from the United Kingdom's Widening Participation Policy. J. Labor Econ. 2020, 38, 183-214. [CrossRef]

76. Perry, B.L.; Martinez, E.; Morris, E.; Link, T.C.; Leukefeld, C. Misalignment of Career and Educational Aspirations in Middle School: Differences across Race, Ethnicity, and Socioeconomic Status. Soc. Sci. 2016, 5, 35. [CrossRef]

77. Tsui, K.-T.; Lee, C.K.J.; Hui, K.-F.S.; Chun, W.-S.D.; Chan, N.-C.K. Academic and Career Aspiration and Destinations: A Hong Kong Perspective on Adolescent Transition. Educ. Res. Int. 2019, 2019, 3421953. [CrossRef]

78. Gore, J.; Holmes, K.; Smith, M.; Southgate, E.; Albright, J. Socioeconomic status and the career aspirations of Australian school students: Testing enduring assumptions. Aust. Educ. Res. 2015, 42, 155-177. [CrossRef]

79. Jacob, J.; Ravindranadan, V. Self-esteem, academic and career aspirations on the basis of socio-economic status of adolescents. Int. J. Indian Psychol. 2018, 6, 75-84. [CrossRef]

80. Gabay-Egozi, L.; Shavit, Y.; Yaish, M. Gender Differences in Fields of Study: The Role of Significant Others and Rational Choice Motivations. Eur. Sociol. Rev. 2014, 31, 284-297. [CrossRef]

81. Rothman, T.; Maldonado, J.M.; Rothman, H. Building self-confidence and future career success through a pre-college transition program for individuals with disabilities. J. Vocat. Rehabil. 2008, 28, 73-83.

82. Legewie, J.; DiPrete, T. High school environments, STEM orientations, and the gender gap in science and engineering degrees. SSRN Electron. J. 2012. [CrossRef]

83. Gutman, L.M.; Akerman, R. Determinants of Aspirations; Centre for Research on the Wider Benefits of Learning: London, UK, 2008.

84. Shahabadkar, P.; Joshi, A.; Lele, V.; Patil, V. Understanding Aspirations of First Year Undergraduate Engineering Students. J. Eng. Educ. Transform. 2021, 34, 86. [CrossRef]

85. Arhin, V. Relationship between career aspirations and study behaviours among second year distance learners of the University of Cape Coast, Ghana. Afr. Educ. Res. J. 2018, 6, 173-180. [CrossRef]

86. DeVeney, B. An investigation into aspects of Thai culture and its impact on Thai students in an international school in Thailand. J. Res. Int. Educ. 2005, 4, 153-171. [CrossRef]

87. Meeussen, L.; Veldman, J.; Van Laar, C. Combining Gender, Work, and Family Identities: The Cross-Over and Spill-Over of Gender Norms into Young Adults' Work and Family Aspirations. Front. Psychol. 2016, 7, 1781. [CrossRef]

88. ILO. The Impact of the COVID-19 Pandemic on Jobs and Incomes in G20 Economies; International Labour Organization: Geneva, Switzerland, 2020.

89. Khampirat, B. The Impact of Work-Integrated Learning and Learning Strategies on Engineering Students' Learning Outcomes in Thailand: A Multiple Mediation Model of Learning Experiences and Psychological Factors. IEEE Access 2021, 9, 111390-111406. [CrossRef]

90. Theerasak, S.-N.; Buratin, K. Comparing Employability Skills of Technical and Vocational Education Students of Thailand and Malaysia: A Case Study of International Industrial Work-Integrated Learning. J. Tech. Educ. Train. 2019, 11, 94-109. [CrossRef] 